\title{
BMJ Open Sleepiness of day workers and watchkeepers on board at high seas: a cross-sectional study
}

\author{
Marcus Oldenburg, ${ }^{\odot}$ Hans-Joachim Jensen
}

To cite: Oldenburg $M$, Jensen H-J. Sleepiness of day workers and watchkeepers on board at high seas: a crosssectional study. BMJ Open 2019;9:e028449. doi:10.1136/ bmjopen-2018-028449

- Prepublication history for this paper is available online. To view these files please visit the journal online (http://dx.doi. org/10.1136/bmjopen-2018028449).

Received 8 December 2018 Revised 29 May 2019 Accepted 12 June 2019

Check for updates

(C) Author(s) (or their employer(s)) 2019. Re-use permitted under CC BY-NC. No commercial re-use. See rights and permissions. Published by BMJ.

Maritime Medicine, Institute for Occupational and Maritime Medicine, Hamburg, Germany

Correspondence to Dr Marcus Oldenburg; marcus.oldenburg@bgv. hamburg.de

\begin{abstract}
Objectives To estimate the prevalence of sleepiness on duty among day workers and watchkeepers on board. Design Cross-sectional survey in a maritime field study. Setting 10 shipping companies with container vessels under German management.

Participants The whole crew ( 75 day workers and 123 watchkeepers) during 18 voyages on 18 different container ships
\end{abstract}

Outcome measures Sleepiness on duty and efficiency of sleep using pupillometry (in a cross-shift design) and the SenseWear armband activity monitor.

Results The watchkeepers showed significantly shorter sleep periods than day workers (5.5hours vs 5.8 hours). The average efficiency of sleep was $69.6 \%$ and significantly lower among watchkeepers (OR 0.48; $95 \% \mathrm{Cl} 0.26$ to 0.88 ). 396 pupillometric examinations were carried out and revealed 88 study members (22.2\%) with a pupillary unrest index (rPUI) in a range characterised as 'unfit for duty' and 110 seafarers $(27.8 \%)$ categorised as 'particular attention required'. The average rPUI was similar between day workers and watchkeepers. The Epworth Sleepiness Scale revealed recent daytime sleepiness in 70 seafarers, which was similarly often stated by day workers and watchkeepers. Based on the Stanford Sleepiness Scale (SSS), a measurable cross-shift increase in the SSS value during the examined shift was observed, especially among watchkeepers. The amount of time already spent on the vessel at the time of the present examination was significantly associated with the rPUI $(p=0.009)$.

Conclusion Sleep periods of both the day workers and the watchkeepers aboard vessels were alarmingly short and sleep efficiency was low. Sleepiness on duty is similarly prevalent among day workers and watchkeepers and seems to depend partly on the cumulative working period on the vessels. Preventive measures need to be taken by the shipping industry to counteract fatigue (eg, by enabling sufficient rest and sleep times).

\section{INTRODUCTION}

Long and irregular working hours each day, combined with sleep deficiency and long periods of work at sea, are crucial risk factors for increased sleepiness on duty among seafarers. ${ }^{12}$ Strong weather conditions can also affect seafarers' performance, increase the risk of error and, consequently, cause

\section{Strengths and limitations of this study}

The present maritime field study shows for the first time the prevalence of seafarers' sleepiness on duty during the sea passage, drawing a distinction between crew members with and without watchkeeping duties.

- The present study analysed seafarers' sleepiness on duty by applying both subjective and objective methods that are less dependent on the participants' motivation (pupillometry, armband activity monitor).

- The study was carried out in a cross-sectional design that does not allow evaluation of long-time effects of sleepiness.

- Due to the various occupational groups on board, the crews are very heterogeneous that makes the interpretation and comparison of sleeping behaviours difficult.

injuries or fatalities to personnel. Psychological strain in maritime professions can also lead to psychosomatic diseases including burnout syndrome or exhaustion. ${ }^{3}$ Some studies have stated that shipping crews suffer from psychophysical exhaustion/strain due to stress and decreased periods and quality of sleep. ${ }^{4}$ Thus, seafaring still ought to be considered a high-risk profession for psychophysical exhaustion. ${ }^{56}$

Three voyage episodes can be distinguished on board: stays in port, river passages and sea passages. During the first two voyage episodes, the seafarers are often exposed to high psychophysical stressors caused by unforeseeable and external demands that possibly need to be addressed at chronobiologically adverse times (eg, embarkation and disembarkation, loading and unloading, exchange of information with port authorities). During the sea passage, the engine room personnel, the electricians and the galley staff can often adhere to a regular working day of 8 hours (day workers). This is better suited to chronobiologically adapted sleep periods and can thus partially compensate for a potential sleep deficiency. ${ }^{7}$ In contrast, due to 
obligatory navigation manoeuvres, nautical officers and a large number of the deck ratings are often required to work in a 24-hour shift system during sea passages (watchkeepers).

Nowadays, merchant ships operating internationally generally run on a 4-hour/8-hour watch shift system. That means that three nautical officers alternate in a system which includes 4 hours on duty and 8 hours off for each of them. Van Leeuwen $e t a l^{8}$ measured the effect of a 4-hour/8-hour watch shift system on the alertness of seafarers in a ship simulator. They observed that especially additional overtime was associated with a subjective and objective increase in sleepiness. The authors also showed sleepiness increasing with time on watch and peaking at the end of a watch."

It has been described that watchkeeping, critical assignments during night-time and irregular working periods can lead to disruptions of the crews' circadian rhythm as a precondition for sleepiness on board. ${ }^{9}$ Dohrmann and Leppin (2017) ${ }^{7}$ performed a systematic analysis and quality assessment of seafarers' fatigue. They observed that working nights was most fatiguing and that fatigue levels were higher towards the end of a watch or shift. According to the review, particularly, the psychosocial work environment (including day workers besides the watchkeepers) had received little attention. However, the monotonous noise of the vessel's engine, the smooth ship's vibrations and the continuous slow ship's movements (during calm weather conditions) can lead to sleepiness of the whole crew on board. Higher levels of exposure to noise and vibrations can also increase sleep troubles/problems and poorer sleep quality when impacting on employees throughout the day. ${ }^{10}$
Working in a maritime setting is characterised by a wide variety of occupations with numerous fatiguing physical and mental strains, depending on the type of job. ${ }^{11}$ The available maritime fatigue studies have only focused on watch officers as crew members who typically also work during night hours. ${ }^{2} 81213$ Thus, there is a lack of knowledge about sleepiness on the high seas among the other shipboard occupational groups, including the day workers. Knowing who is affected by severe sleepiness on board is of great importance to facilitate its prevention.

The present maritime field study analysed for the first time the prevalence of seafarers' sleepiness on duty during the sea passage, with a distinction between day workers and watchkeepers on board.

\section{METHODS \\ Study sample}

A medically trained scientist accompanied 18 sea voyages on 18 different container ships operating in the Baltic Sea and examined the crew members on board. Two hundred and six out of 225 seafarers took part in the study (response rate 91.6\%). Only the results of those 198 seafarers were included who could be interviewed and examined (pupillometry) in a cross-shift design (both before the beginning and after the end of their shift). Taking part in this study was voluntary and the individual data was pseudonymised. No patients were involved in this study. All participants gave their written informed consent before taking part in this study.

The 198 seafarers were classified into two occupational groups ( 75 day workers and 123 watchkeepers) (table 1 ). The median age of the exclusively male study sample was 36.7 years (19-67 years) and significantly higher among

Table 1 Demographic and lifestyle parameters by occupational groups on board

\begin{tabular}{|c|c|c|}
\hline & $\begin{array}{l}\text { Day workers ( } 54 \text { engine room personnel, } \\
16 \text { electricians, five galley staff) }\end{array}$ & $\begin{array}{l}\text { Watchkeepers (46 nautical officers, } 77 \\
\text { deck ratings) }\end{array}$ \\
\hline Number, n (\%) & 75 (37.9\%) & $123(62.1 \%)$ \\
\hline Age; median years (min-max) & $44(19-67)$ & $35(19-63)$ \\
\hline Body mass index; median (min-max) & $26(19-40)$ & $24(17-36)$ \\
\hline \multicolumn{3}{|l|}{ Morning-Evening-Questionnaire, n (\%) } \\
\hline Morning type & $45(60.0 \%)$ & $68(55.2 \%)$ \\
\hline Intermediate type & $24(32.0 \%)$ & $46(37.4 \%)$ \\
\hline Evening type & $6(8.0 \%)$ & $9(7.4 \%)$ \\
\hline \multicolumn{3}{|l|}{ Origin; n (\%) } \\
\hline European & $38(50.7 \%)$ & $47(38.2 \%)$ \\
\hline Southeast Asian & $37(49.3 \%)$ & $76(61.8 \%)$ \\
\hline Married; n (\%) & $53(70.7 \%)$ & $87(70.7 \%)$ \\
\hline Children; n (\%) & $53(70.7 \%)$ & $82(66.7 \%)$ \\
\hline \multicolumn{3}{|l|}{ Smoking status; n (\%) } \\
\hline Never smoked & $36(48.0 \%)$ & $65(52.8 \%)$ \\
\hline Former smoker/smoker & 39 (52.0\%) & $58(47.2 \%)$ \\
\hline
\end{tabular}


the day workers. Furthermore, the day workers had a somewhat higher body weight than the watchkeepers. No differences were observed in the circadian preference when comparing watchkeepers with day workers. The difference between the two occupational groups in terms of their marital status and the presence of children was not noteworthy. Forty-nine per cent of the seafarers either smoked or were former smokers.

\section{Patient and public involvement}

The present study focused on the sleepiness of shipboard crews; patients and/or public were not the target group of this study. Previous studies revealed that sleepiness constitutes one of the major problems among seafarers. All German shipping companies owning container ships were invited to participate in this study. Ten shipping companies agreed and put 18 different container ships at our disposal (one ship of companies A, B, C and D, two ships of companies E, F, G and $\mathrm{H}$ and three ships of companies I and J participated).

All seafarers on board of these vessels were informed about our study design, aim and content and were encouraged to participate (participation rate 88.0\%). After completion of our board examination, an individual medical report was created and sent to each of the accepting seafarers to their home address.

To assess long-term effects on sleep during their current period on board, the participants were additionally grouped in respect of their stay on board at the time of examination ( $<2$ months, $2-5$ months and $>5$ months).

\section{Examination procedure}

All seafarers taking part in the study were examined with the SenseWear armband monitor and pupillometry both during shifts and during time off (including sleep time). These devices were selected because they did not considerably disturb the crew's daily routines (low weight, no cable connection, easy use), which was a precondition. The present study monitored the sleep of all seafarers in a continuous mode during a period of at least 72 hours of observation. An observation time of at least 3 days during the sea passage was chosen because of the known variations of sleep quality on a daily basis.

The average period of wearing the armband monitor was 66.3 hours (SD 14.8 hours) ( $>92 \%$ of observation time) and did not differ between the occupational groups. The pupillometric examination took place within this observation period.

\section{Efficiency of sleep}

The SenseWear armband activity monitor is a device that weighs $82 \mathrm{~g}$ and is worn on the right upper arm just above the triceps muscle according to its validation requirements. While wearing the armband monitor, the seafarers could easily operate the device for themselves without support from the shipboard examiner. The monitor is designed to analyse the profile of physical activity (movement, lying down or sleeping). The collected information allows the estimation of sleep efficiency by establishing the ratio of the duration of sleep and the time spent lying down. Thus, efficiency of sleep expresses the time spent actually sleeping while lying down.

The armband monitor has already been successfully applied in many studies as a detector of sleep. ${ }^{14-19}$ Current studies reveal that the total sleep time and time in bed correlate significantly between the measurements of the armband monitor and the polysomnography $(\mathrm{p}<0.001)$; the armband has proved to be superior in comparison with other commercially available activity monitors. ${ }^{16}$

\section{Pupillometry}

The device Fit-For-Duty by AmTech was used to conduct pupillometric examinations..$^{20}$ The Pupillographic Sleepiness Test is considered an objective method for documenting sleepiness by monitoring spontaneous and unconscious oscillations of the pupil without stimulating light. The result is a pupillogram, which can be used to deduct the pupillary unrest index (rPUI). This parameter therefore is an objective measure for the variance of the diameter of the pupil. A recent study suggested the Pupillographic Sleepiness Test as a reliable measurement for detecting drowsiness-related impairment. ${ }^{21}$

The rPUI is compared with standard values. Results $<1.02$ are considered normal. 'Particular attention required' is the characterisation of results $\geq 1.02$ and $<1.53$. An index $\geq 1.53$ is rated as 'unfit for duty'. This methodology has repeatedly been used in scientific studies to assess sleepiness. ${ }^{22-24}$

During a sea passage, the pupillometric examination was performed twice according to a cross-shift design for all 198 seafarers included in the study sample. The chosen sea passages lasted for at least 24 hours and therefore allowed a regular operation of the vessel and predictable working procedures. The pupillometric cross-shift examination took place $15 \mathrm{~min}$ before the respective shift started and directly after it ended so that that shift was neither shortened nor disturbed by this examination. In general, it is not likely that the seafarers were distinctly disturbed by the examination with the chosen devices or by the presence of the medical staff on board.

The engine room personnel, the electricians and the galley staff (without watchkeeping duties) were examined during an average work shift that lasted 8 hours (most likely from 8:00 hours to 17:00 hours including a lunch break of 1 hour). As watchkeepers have two work units per day-each of them about 4 hours (six shift periods: $0-4$ hours, $4-8$ hours, $8-12$ hours, $12-16$ hours, 16-20 hours and 20-24hours) - a split sleeping time is often observed in this occupational group. The watchkeepers were examined during a randomly selected shift period with the aim of achieving an equal representation of these periods (about 20 watchkeepers/shift period). For the assessment of cross-shift reactions, it was unavoidable to compare the PUI and SSS between two occupational groups with different lengths of working times. 


\section{Questionnaire}

In the framework of a standardised interview, all seafarers were asked about their demographic data, their subjective physical and mental stress level, their sleep period before the examined shift and their current working time. Additionally, daytime sleepiness was estimated by using the Epworth Sleepiness Scale (ESS) ${ }^{25}$ This is a self-administered questionnaire which is shown to provide a measurement of the subject's general level of daytime sleepiness. Retrospectively, the probability of nodding off or falling asleep in eight typical everyday situations is investigated. Furthermore, the Stanford Sleepiness Scale was used as a self-rating scale to quantify progressive stages of sleepiness. ${ }^{26}$ Individual circadian fluctuations in sleepiness and alertness can be determined through repetition in intervals. In the present study, this scale assessed the sleepiness before and after a shift. Finally, the seafarers filled in the Morning-Evening-Questionnaire (rMEQ) for the assessment of the circadian preference. ${ }^{27} 28$ This questionnaire evaluates against individual differences in the circadian rhythm. Responses to the questions are combined to form a composite score that indicates the degree to which the respondent favours morning versus evening.

\section{Statistics}

Statistic analysis was performed with SPSS (V.24, IBM Corporation). The Shapiro-Wilk test was used to test for normal distribution of data. Where variables were not normally distributed, non-parametric tests (MannWhitney U test, Wilcoxon test) were used, otherwise the t-test was applied in the case of normal distribution. The $\mathrm{X}^{2}$ test was used to analyse differences in frequencies of parameters. Crude OR including 95\% CIs was calculated by binary logistic regression. For adjustment reasons, age, rank (officer vs rating), the examination time of day and duration of stay on board at the time of examination were added. Furthermore, correlations were analysed by using the Spearman test.

All indicated $p$ values were two-sided and a $p$ value of $<0.05$ was regarded as statistically significant.

\section{RESULTS}

The number of months day workers had already spent on the vessel at the time of examination and during their current contract was similar to that of watchkeepers. In particular, the stratification of the seafarers in tertiles concerning their recent stay on board did not reveal any differences (table 2).

The ESS showed that 70 seafarers $(35.4 \%)$ had recently been suffering from daytime sleepiness. The ESS value increased significantly ( $p=0.004)$ with the length of stay on board. No differences were observed when differentiating according to the obligation to perform watchkeeping duties $(p=0.113)$. Younger seafarers below the age median of 37 years indicated daytime sleepiness more often than older colleagues $(p=0.014)$.

\section{Cross-shift examinations}

To analyse the recent alertness attributed to a representative shift, 198 seafarers were asked to participate in a cross-shift examination. According to the results of the armband monitor, the cumulative sleep time before the examined shift (including split sleep episodes) lasted for 5.6hours (SD 1.0) per 24-hour period, while watchkeepers had significantly shorter sleep durations compared with the day workers (table 3). The working hours during the examined shift were significantly lower among watchkeepers. Concerning their subjective stress level during the shift examined, significantly more watchkeepers experienced mental demands than day workers (OR 2.35; 95\% CI 1.24 to 4.44). After adjustment for age,

Table 2 Stay on board and subjective assessment for daytime sleepiness

\section{Occupational groups}

Day workers $(n=75) \quad$ Watchkeepers $(n=123) \quad P$ value

\begin{tabular}{|c|c|c|c|}
\hline \multicolumn{4}{|l|}{ Stay on board } \\
\hline At the time of examination; median months (min-max) & $3(1-12)$ & $3(0-11)$ & $0.837^{\star}$ \\
\hline \multicolumn{4}{|l|}{ Frequency according to tertile; $\mathrm{n}(\%)$} \\
\hline$>2$ and $\leq 5$ months & $28(37.3 \%)$ & $45(36.3 \%)$ & \multirow{2}{*}{$0.973+$} \\
\hline$>5$ months & $19(25.3 \%)$ & $33(26.8 \%)$ & \\
\hline \multicolumn{4}{|l|}{ Epworth Sleepiness Scale, median (min-max) } \\
\hline Score value (SD) $\ddagger$ & $8(0-15)$ & $8(0-21)$ & $0.113^{*}$ \\
\hline$\geq$ Cut-off off value (10), n (\%) & $26(34.7 \%)$ & $44(35.8 \%)$ & $0.875^{\dagger}$ \\
\hline
\end{tabular}

*Mann-Whitney U test.

$\dagger \mathrm{X}^{2}$ test.

$\ddagger$ Sleepiness scale from 0 ('no chance to doze in') up to 24 ('maximum chance to doze in'). 
Table 3 Cross-shift examination concerning sleep characteristics

\section{Occupational groups}

Day workers ( $n=75) \quad$ Watchkeepers $(n=123) \quad$ Crude OR ${ }^{*}(95 \% \mathrm{Cl}) \quad$ Adjusted OR† $(95 \% \mathrm{Cl})$

\begin{tabular}{|c|c|c|c|c|}
\hline \multicolumn{5}{|c|}{ Time periods in the context of the current pupillometric examination, mean hours (SD) } \\
\hline Sleep period before $\ddagger$ & $5.8(1.1)$ & $5.5(1.0)$ & 0.85 (0.78 to 0.92$)$ & $0.88(0.80$ to 0.95$)$ \\
\hline Working hours examined & $9.5(1.5)$ & $4.9(1.6)$ & $0.56(0.43$ to 0.88$)$ & $0.57(0.46$ to 0.92$)$ \\
\hline Physical§ & $48(64.0 \%)$ & $78(63.4 \%)$ & $0.96(0.52$ to 1.79$)$ & $0.51(0.24$ to 1.08$)$ \\
\hline Mentalף & $41(54.7 \%)$ & $94(76.4 \%)$ & 2.35 (1.24 to 4.44$)$ & $2.18(1.08$ to 4.40$)$ \\
\hline \multicolumn{5}{|l|}{$\mathrm{SSS}^{\star *}$, mean (SD) } \\
\hline Cross-shift $†$ & $2.6(1.4)$ & $3.1(1.7)$ & 0.73 (0.48 to 1.10$)$ & 0.84 (0.55 to 1.29$)$ \\
\hline \multicolumn{5}{|l|}{ Time depending } \\
\hline Before the shift & $2.5(1.4)$ & $2.6(1.5)$ & 1.07 (0.59 to 1.95$)$ & 0.91 (0.49 to 7.70$)$ \\
\hline \multicolumn{5}{|l|}{ Time depending } \\
\hline Before the shift & $1.14(0.67)$ & $1.12(0.62)$ & $0.96(0.52$ to 1.74$)$ & $0.86(0.46$ to 1.61$)$ \\
\hline After the shift & $1.13(0.66)$ & $1.23(0.65)$ & 1.55 (0.85 to 2.84$)$ & 1.31 (0.70 to 2.46$)$ \\
\hline \multicolumn{5}{|c|}{ Level $(n=396)$ of sleepiness on dutyt† $n(\%)$} \\
\hline Noneł‡ & $78(52.0 \%)$ & $120(48.8 \%)$ & 0.789 & \\
\hline Particular attention required§§ & $39(26.0 \%)$ & $71(28.9 \%)$ & & \\
\hline Unfit for dutyףी & $33(22.0 \%)$ & $55(22.3 \%)$ & & \\
\hline
\end{tabular}

Significant findings are in bold.

*The crude OR bases on the median of parameters and includes differences between occupational groups and the examination time of day. †Adjusted for age, rank (officer vs rating) and duration of stay on board at the time of examination.

$\ddagger$ According to measurements with the armband monitor, related to an average 24-hour period.

$\S$ 'Have you experienced physical stress during the examined shift?’

ף'Have you experienced mental stress during the examined shift?'

**SSS from 1 ('feel active and vital') up to 7 ('almost dreaming/falling asleep').

††All values exploited (before and after the shift).

抽Ul<1.02.

$\S \S \mathrm{rPUI} \geq 1.02$ and $<1.53$.

$\eta \Uparrow \mathrm{rPUI} \geq 1.53$.

rPUI, pupillary unrest index; SSS, subjective sleepiness assessment.

ranking, examination time of day and recent number of months at the time of investigation, this elevated risk for mental stress remained significant among watchkeepers.

During the examined shift, the average sleep efficiency was $69.3 \%$ and was significantly lower among watchkeeping seafarers than day workers (OR 0.48 ; 95\% CI 0.26 to 0.88 ). This finding was independent of the age, ranking, time of day of the examination and the recent duration of shipboard stay; $63.7 \%$ of the participating seafarers stated that they had consumed coffee within the past 4 hours before our pupillometric examination on board irrespective of their occupational group.

Before their shift, the mean value on the Stanford Sleepiness Scale (SSS) was 2.6 (SD 1.4) (2='functioning at high levels, but not fully alert'; $3=$ ='awake, but relaxed; responsive but not fully alert'); after the work shift, the level of sleepiness was significantly higher (3.2 (SD 1.8))
(Wilcoxon test: $\mathrm{p}=0.001$ ) indicating a measurable increase in the subjective sleepiness in the course of a shift. This was especially true for watchkeepers although the length of their working time was much shorter than that of day workers (table 3). Consequently, more watchkeepers reported current sleepiness than day workers after the examined shift.

A remarkable number of 35 seafarers $(17.7 \%)$ reported a level of sleepiness on duty of $6 / 7$ on the SSS ( $6=$ "sleepy, woozy, fighting sleep, prefer to lie down'; $7=$ "no longer fighting sleep; sleep onset soon; having dream-like thoughts') after their shift. According to SSS, more young seafarers considered themselves to be tired (cross-shift SSS of all crew members below and above the median age of 37 years: 3.1 vs 2.6; $\mathrm{p}=0.011$ ). Focusing on the group of watchkeeping seafarers, those who were on duty between 00:00-04:00 hours and 04:00-08:00 hours more 
often displayed severe sleepiness on duty after their shift (SSS $\geq 5)$ ( $72.2 \%$ and $50.0 \%$, respectively).

The 396 pupillometric examinations $(15 \mathrm{~min}$ before and after a shift) revealed that the change in rPUI values during the cross-shift observation did not reach a significant level in intraindividual comparison (mean rPUI before vs after the working shift: 1.14 vs 1.19; cross-shift rPUI change: $\mathrm{p}=0.355$ ). After stratification, the intraindividual cross-shift change in rPUI values was also not dependent on the occupational groups (table 3), while the different lengths of working time has to be taken into account.

The objective sleepiness on duty in the study sample was not dependent on age (only a slight tendency for younger seafarers after shift; $\mathrm{p}=0.064$ ). During the examination, 12 seafarers fell asleep and therefore were assigned to the group 'unfit for duty'. The pupillary unrest index in 88 examinations showed the seafarers were 'unfit for duty'; additionally 'particular attention required' was classified in 110 cases $(27.8 \%)$. Therefore, only half of the examinations were 'normal'. No differences were observed in the pupillary unrest index between seafarers with and without watchkeeping duties.

In concordance to their subjective self-report in SSS, watchkeepers displayed somewhat higher rPUI values after the shift than day workers (table 3). The analysis of the correlation of the subjective assessment of sleepiness on duty (SSS) with the objective measures of pupillometry only revealed a weak correlation after the shift $(\mathrm{r}=0.185 ; \mathrm{p}=0.009)$.

Within the group of watchkeepers, stronger sleepiness on duty (rPUI $\geq 1.2$ ) after a shift lasting from 00:00 to 04:00 hours and from 04:00 to 08:00 hours was observed ( $75.0 \%$ and $55.6 \%$, respectively).

Regardless of the occupational groups, the objective sleepiness on duty (rPUI) did not correlate to the cumulative sleep over a 24-hour period before the examined shift, the sleep efficiency and the objective assessment of the ship's motion according to the ship's journal parameters. An association was observed, however, between the duration of time already spent on board at the time of the seafarers' examination and the rPUI $(\mathrm{p}=0.009)$. The stratification according to the duration of stay on board indicates that the association was especially true for those seafarers with a longer stay on the vessels (pre-shift rPUI after stay of less than 2 months, $2-5$ months and more than 5 months: 1.06, 1.09 and, much higher, 1.32). The bivariate grouping of the crew according to their stay of less versus more than 5 months showed significant pre-shift differences in rPUI (1.08 vs $1.32 ; \mathrm{p}=0.002)$.

\section{DISCUSSION}

Being a seafarer requires strong mental stability and a robust physical constitution, along with an adaptive and flexible attitude. However, stress and fatigue can hinder maritime professionals in performing effectively. ${ }^{29}$ Seafarers spend both their working and leisure time over a couple of months in the restricted shipboard environment that can impact sleep quality and lead to sleepiness. ${ }^{5}$ In the present study, a significantly lower sleep efficiency averaging at $69.3 \%$ and a higher SSS after the shift were found among watchkeepers compared with day workers. In addition, the examinations carried out on board objectified critically short durations of the seafarers' sleep average ( 5.6 hours per 24-hour period) particularly among watchkeepers.

Especially the short sleeping times correspond very well with the results of international studies. ${ }^{30}$ Sleep periods on board are often interrupted (potentially due to ship's movements or sudden noise evoked by the handling of containers in harbours). ${ }^{31}$ These effects can explain why many seafarers, including day workers, suffer from sleepiness on the high seas. The sleep interruptions are particularly often an inevitable consequence of the watch shift requirements with two 4-hour working shifts per day. Thus, on any watch system, it is common that seafarers have several sleep episodes per 24-hour period. Daytime sleep is usually much less efficient than sleep obtained at the circadian nadir. It can be assumed that some watchkeepers have problems falling asleep after a stressful working day (with scarcely any opportunities for sleep); this results in decreased sleep efficiency. Split sleep among watchkeepers can also not be excluded as the cause of this low sleep efficiency.

Although this study has not proved that sleepiness on duty depends directly on disturbances of the sea during passages, we measured generally low sleep efficiency. This means that not only the amount but also the quality of sleep is insufficient among the examined seafarers on board. Frequent sleep disruptions can impair alertness to a great degree and consequently lead to an increased risk of accident on board. ${ }^{32}$

Despite similar physical stress levels, the crew members with watchkeeping duties experienced mental stress subjectively more frequently than day workers. This was probably due to their reduced and interrupted sleep time as well as their high job responsibility, which represents a distinct mental stressor. Correspondingly, the watchkeepers starting with a subjective sleepiness level similar to that of the day workers had a significantly more pronounced increase in their sleepiness level after the cross-shift examination. Although no significance level was reached, the cross-shift pupillometry of watchkeepers also indicated a higher level of objective sleepiness after the shift than that of day workers. In this context, the difference in the length of examined working time between day workers and watchkeepers has to be highlighted. The watchkeepers' higher value for SSS and, by trend, for PUI after the examined shift is remarkable as they had worked a considerably shorter time than the day workers. Thus, these differences are surely underestimated in this study.

According to Wilhelm (2008), ${ }^{33}$ severe sleepiness is displayed by drivers who did not sleep during the chronobiologically relevant time frame (0:00 hours-05:00 hours). 
In the maritime setting, this especially applies to watchkeepers. These crew members, who are on duty during the inconvenient time frames between 0:00-04:00 hours and 04:00-08:00 hours, reported the expected subjective severe sleepiness, which was also objectively measured using pupillometry. In this context, it has to be taken into account that most fatigue-induced shipping disasters take place in these time frames. ${ }^{34}$

According to the results of the rMEQ in the present study, the morning type was over-represented in the study group. Due to the fact that their work shifts on board often begin early in the morning over several months in a stretch, many seafarers are surely adapted to this daily rhythm and subjectively feel particularly fit in the early morning hours. This is a hypothesis for the skewed distribution towards the morning type in our study that needs confirmation in further field studies on board.

Watchkeepers are habitual shift workers, often experiencing circadian misalignment due to their irregular work/rest schedules. This might be one explanation as to why the small number of available maritime field studies about seafarers' fatigue has exclusively focused on watchkeepers. Importantly, this study demonstrates that day workers also often experience severe sleepiness; more than $20 \%$ of both the watchkeepers and the day workers were characterised as 'unfit for duty' during their regular shift and only every second pupillary measurement was regarded normal. The fact that 12 seafarers had fallen asleep during the 11 min pupillary examination and that 35 crew members regarded themselves as very sleepy post-shift ( $S S S \geq 6$ ) confirms these alarming pupillometric results. In light of the strong impact on the ships' safety, further studies are urgently needed to examine and counteract the sleepiness of both the shipboard watchkeepers and the day workers.

Furthermore, this study observed that the duration already spent on the vessel at the time of the examination correlated with the PUI. This finding could indicate a cumulative effect on the seafarers' sleepiness. Officers normally have far shorter periods on board than ratings (averaging 2.5 vs 4.1 months in a row). Daily sleepiness as a consequence of high work strain lasting for many months seems to be plausible. According to the present results, working periods below 5 months in a row seem to be reasonable for seafarers. Further studies are required to evaluate this hypothesis and to determine recommendations for maximum working periods on board.

Subjective assessments of sleepiness only displayed a weak correlation with the objective pupillometric results. This could lead to a misjudgement of the seafarers' current psychophysical performance, which might also have safety implications. Younger and less experienced crew members reported more severe sleepiness on duty but did not display differences in their pupillometric measurements. In view of the frequently described high prevalence of fatigue-related accidents in seafaring, not only a high level of psychophysical stress but also a misjudgement of their alertness is assumed. Thus, it is recommended to use complementary objective methods besides questionnaires in studies to determine the level of fatigue among examined employees. Future studies should also explore possibilities and evaluate acceptance by the crew to develop more flexible shift scheduling that allows the consideration of circadian preferences and, possibly, individual preferences of the watchkeeping seafarers.

\section{Limitations}

The present study has some limitations that need to be addressed. First, the sample size of this study is rather small, but in comparison to other available maritime studies, the examined seafarer population is far larger. Second, the study was carried out in a cross-sectional design that does not allow the evaluation of long-time effects of sleepiness. Due to the permanently changing shipping crews on the vessels, it is hardly possible to arrange long-time follow-up examinations of a noteworthy proportion of seafarers. Third, due to the various occupational groups on board, the crews are very heterogeneous and that makes the interpretation and comparison of sleeping behaviours difficult, also when considering the large interindividual and intraindividual variability in sleep. Fourth, the present study design does not provide information about the seafarers' sleep architecture. Sleep loss is generally compensated by changing the sleep architecture towards more the so-called slow-wave sleep.

The armband monitor used is mainly suitable for measuring bed rest ${ }^{35}$ and has only a limited informative value about sleep architecture, which is normally measured in sleep laboratories ashore, for example, using polysomnographic techniques. ${ }^{36}$ In maritime field studies, however, the use of such extensive examinations (only one measurement per night) does not appear to be very suitable on board. Furthermore, the determination of lying time with this monitor may be somewhat imprecise so that an underestimation of the sleep efficiency cannot be excluded. Although the sleep diaries frequently used for sleep assessment are only subjective procedures, in further studies, the armband monitor examination should be accompanied by the use of sleep diaries as they allow checking the start and end times of sleep.

Moreover, pupillometry has yet not been established as a reliable screening test for sleepiness. ${ }^{36}$ Particularly, sleep latency or sleep architecture are the domains of extensive examinations in sleep laboratories ashore and were not the focus of the present maritime field study. Additionally, the PUI correlated with the seafarers' subjective statements. Further studies are recommended to evaluate the validity of these devices for their use in maritime field settings as well as to check their suitability on board and their acceptance by the seafarers on the high seas.

Despite these limitations, the present study analyses for the first time the prevalence of sleepiness in seafarers with and without watchkeeping duties; the findings require further confirmation in a larger cohort. Furthermore, the present maritime field study analysed the prevalence 
of seafarers' sleepiness on duty by applying various subjective and objective methods. Up to now, most maritime studies about seafarers' sleepiness have not been carried out on board vessels and only rely on subjective methods. ${ }^{37}$ Questionnaires are, however, subjective instruments, consequently depending on self-reported data, so that under-reporting might have occurred.$^{38}$ Additionally, these subjective instruments do not reveal biophysiological differences that might promote the understanding of sleepiness on board. ${ }^{21} 39$

Nowadays, a variety of subjective and objective instruments exist for assessment of excessive daytime sleepiness, including structured sleep history, sleep logs and sleep questionnaires. The multiple sleep latency test, for example, is often used as an objective measurement to evaluate sleep propensity. However, in view of the large overlap between healthy subjects and subjects with sleep disorders, its use to assess sleepiness is questionable. Furthermore, its results are often jeopardised by motivational influences and the last nap effect. ${ }^{37}$ Consequently, a feasible and convenient method that is less dependent on motivation - such as the pupillometry used in this studyseems to constitute an enrichment in field studies. ${ }^{21}$

\section{Implications for clinicians and policymakers}

Fatigue in the maritime setting could be counteracted by strict compliance with and monitoring of the obligatory rest and sleep times. According to Allen $e t a l,{ }^{37}$ it is not uncommon in seafaring for legal obligations to be neglected, for example, by ignoring the minimum safety levels for crewing on board. To reduce the seafarers' workload on board during the vessel's stay in port, some job duties could be transferred to land-based workers ashore.

In light of the frequently observed sleepiness on duty within the study sample, training should be offered for shipboard crews to improve sleep hygiene and techniques to support short-term relaxation, such as power napping. This training should be accompanied by the strengthening of the seafarers' individual resources (eg, training to cope with stress for health promotion) to enable them to compensate for the inevitable psychophysical strain on board. Considering the present results, limiting the work periods of seafarers (perhaps to a maximum of 5 months) might be an essential preventive measure in a maritime setting.

Acknowledgements The authors would like to thank the seafarers and the shipping companies for taking part in this study. Many thanks are also owed to $\mathrm{J}$ Hedtmann, C Felten and B Neubauer from the BG Verkehr for their support and the funding.

Contributors $\mathrm{MO}$ and $\mathrm{H}$-JJ gave substantial contributions to the conception or design of the work or the acquisition, analysis or interpretation of data. They were equally involved in drafting the work or revising it critically for important intellectual content. Both authors gave their final approval of the version to be published.

Funding This study was funded by the Berufsgenossenschaft für Transport und Verkehrswirtschaft ('BG Verkehr'), Hamburg. The funder has no involvement in the study design, the collection, analysis and interpretation of data, the writing of the report and the decision to submit the paper for publication.

Competing interests None declared.
Patient consent for publication Not required.

Ethics approval The study was approved by the Ethics Committee of the Hamburg Medical Association (no. PV4395).

Provenance and peer review Not commissioned; externally peer reviewed.

Data sharing statement № additional data are available.

Open access This is an open access article distributed in accordance with the Creative Commons Attribution Non Commercial (CC BY-NC 4.0) license, which permits others to distribute, remix, adapt, build upon this work non-commercially, and license their derivative works on different terms, provided the original work is properly cited, appropriate credit is given, any changes made indicated, and the use is non-commercial. See: http://creativecommons.org/licenses/by-nc/4.0/.

\section{REFERENCES}

1. Oldenburg $M$, Jensen $H J$, Latza $U$, et al. Seafaring stressors aboard merchant and passenger ships. Int J Public Health 2009;54:96-105.

2. Lützhöft M, Dahlgren A, Kircher A, et al. Fatigue at sea in Swedish shipping-a field study. Am J Ind Med 2010;53:n/a-40.

3. Oldenburg M, Hogan B, Jensen HJ. Systematic review of maritime field studies about stress and strain in seafaring. Int Arch Occup Environ Health 2013;86:1-15.

4. Jepsen JR, Zhao Z, van Leeuwen WM. Seafarer fatigue: a review of risk factors, consequences for seafarers' health and safety and options for mitigation. Int Marit Health 2015;66:106-17.

5. Hystad SW, Eid J. Sleep and fatigue among seafarers: the role of environmental stressors, duration at sea and psychological capital. Saf Health Work 2016;7:363-71.

6. Gander P, van den Berg M, Signal L. Sleep and sleepiness of fishermen on rotating schedules. Chronobiol Int 2008;25:389-98.

7. Dohrmann SB, Leppin A. Determinants of seafarers' fatigue: a systematic review and quality assessment. Int Arch Occup Environ Health 2017;90:13-37.

8. van Leeuwen WM, Kircher A, Dahlgren A, et al. Sleep, sleepiness, and neurobehavioral performance while on watch in a simulated 4 hours on/8 hours off maritime watch system. Chronobiol Int 2013;30:1108-15.

9. Akerstedt T. Shift work and disturbed sleep/wakefulness. Occup Med 2003;53:89-94.

10. Velasco Garrido M, Mette J, Mache S, et al. A cross-sectional survey of physical strains among offshore wind farm workers in the German exclusive economic zone. BMJ Open 2018;8:e020157.

11. Velasco Garrido M, Mette J, Mache S, et al. Sleep quality of offshore wind farm workers in the German exclusive economic zone: a crosssectional study. BMJ Open 2018;8:e024006.

12. Härmä $M$, Partinen $M$, Repo R, et al. Effects of $6 / 6$ and $4 / 8$ watch systems on sleepiness among bridge officers. Chronobiol Int 2008;25:413-23.

13. Eriksen CA, Gillberg M, Vestergren P. Sleepiness and sleep in a simulated "six hours on/six hours off" sea watch system. Chronobiol Int 2006;23:1193-202.

14. Cox NS, Pepin V, Holland AE. Greater sleep fragmentation is associated with less physical activity in adults with cystic fibrosis. $J$ Cardiopulm Rehabil Prev 2019;39:1.

15. Lopez GA, Brønd JC, Andersen LB, et al. Validation of SenseWear Armband in children, adolescents, and adults. Scand J Med Sci Sports 2018;28:487-95.

16. Gruwez A, Libert W, Ameye L, et al. Reliability of commercially available sleep and activity trackers with manual switch-to-sleep mode activation in free-living healthy individuals. Int $J$ Med Inform 2017;102:87-92.

17. Peacock JG, Vine RL, McDonald JS, et al. Armband activity monitor data do not correlate with reported pain scores in patients receiving vertebroplasty. J Neurointerv Surg 2017;9:905-9.

18. Eagles AN, Lovell DI. Changes in sleep quantity and efficiency in professional rugby union players during home-based training and match play. J Sports Med Phys Fitness 2016;56:565-71.

19. Kölling S, Wiewelhove T, Raeder C, et al. Sleep monitoring of a sixday microcycle in strength and high-intensity training. Eur J Sport Sci 2016;16:507-15.

20. Różanowski K, Bernat M, Kamińska A. Estimation of operators' fatigue using optical methods for determination of pupil activity. Int $J$ Occup Med Environ Health 2015;28:263-81.

21. Maccora J, Manousakis JE, Anderson C. Pupillary instability as an accurate, objective marker of alertness failure and performance impairment. J Sleep Res 2019;28:e12739. 
22. Wilhelm B, Bittner E, Hofmann A, et al. Short-term reproducibility and variability of the pupillographic sleepiness test. Am J Hum Biol 2015;27:862-6

23. Regen F, Dorn $\mathrm{H}$, Danker-Hopfe $\mathrm{H}$, et al. Association between pupillary unrest index and waking electroencephalogram activity in sleep-deprived healthy adults. Sleep Med 2013;14:902-12.

24. Eggert T, Sauter C, Popp R, et al. The pupillographic sleepinesstest in adults: effect of age, gender, and time of day on pupillometric variables. Am J Hum Biol 2012;24:820-8.

25. Johns MW. Sleepiness in different situations measured by the Epworth Sleepiness Scale. Sleep 1994;17:703-10.

26. Hoddes E, Zarcone V, Smythe H, et al. Quantification of sleepiness: a new approach. Psychophysiology 1973;10:431-6.

27. Horne JA, Ostberg $O$. A self-assessment questionnaire to determine morningness-eveningness in human circadian rhythms. Int $J$ Chronobiol 1976;4:97-110.

28. Randler C, Díaz-Morales JF, Rahafar A, et al. Morningnesseveningness and amplitude - development and validation of an improved composite scale to measure circadian preference and stability (MESSi). Chronobiol Int 2016;33:832-48.

29. Panganiban AU, Garcia OB. Contributory to stress and fatigue of Filipino seafarers. Asia Pacific Journal of Maritime Education 2017;3.

30. Shattuck NL, Matsangas P. Sunlight exposure, work hours, caffeine consumption, and sleep duration in the naval environment. Aerosp Med Hum Perform 2017;88:579-85.
31. Khoo IH. Study of the noise pollution at container terminals and the surroundings. Metrans 2011.

32. Leger $D$. The cost of sleep-related accidents: a report for the National Commission on Sleep Disorders Research. Sleep 1994:17:84-93.

33. Wilhelm BJ. [Pupillography for the assessment of driver sleepiness]. Klin Monbl Augenheilkd 2008;225:791-8.

34. Marine Accident Investigation Branch. Bridge watchkeeping safety study by the Marine Accident Investigation Branch (MAIB). https:// assets.publishing.service.gov.uk/government/uploads/system/ uploads/attachment_data/file/377400/Bridge_watchkeeping_safety_ study.pdf (Accessed on Feb 2019).

35. Lee JM, Byun W, Keill A, et al. Comparison of wearable trackers' ability to estimate sleep. Int J Environ Res Public Health 2018;15:1265.

36. Yamamoto K, Kobayashi F, Hori R, et al. Association between pupillometric sleepiness measures and sleep latency derived by MSLT in clinically sleepy patients. Environ Health Prev Med 2013;18:361-7.

37. Allen P, Wadsworth E, Smith A. The prevention and management of seafarers' fatigue: a review. Int Marit Health 2007;58(1-4):167-77.

38. Littner MR, Kushida C, Wise M, et al. Practice parameters for clinical use of the multiple sleep latency test and the maintenance of wakefulness test. Sleep 2005;28:113-21.

39. Urschitz MS. Assessing objective daytime sleepiness in children and adults: do we have appropriate instruments? Sleep Med 2013;14:812-3. 